\title{
BUSINESS AND THE ROBINSON-PATMAN ACT: THE FIRST YEAR
}

\author{
Edwin B. GrorgB*
}

\section{Lack of Pattern in Robinson-Patman Developments}

The Robinson-Patman Act's first year of life has been a turbulent one. This is not an unusual consequence of laws attempting to control the intimate details of business conduct. And the insinuation of this particular law into the private lives of buyers and sellers has been such as to cause a lifting of eyebrows even among those favoring a close affinity between law and business. Some of them feel that in this case the familiarity is a trifle excessive. This however is a question of degrees. More fundamental is the probable feeling of a great majority of business men, and perhaps of lawyers and economists, that the law was provoked by cumulative abuse of the privilege of price favoritism in behalf of large buyers. They approve the principle of control but have been somewhat dazed by its degree.

The first result of the Robinson-Patman Act was a prolonged cacophony of speculation concerning its meaning. It has been a great age for lawyers, except for the fact that they have been hardly less baffled than their clients. "Yes and No" has been the grave concensus of legal opinion on most of the controversial points. This disturbance has not yet subsided, except as it has yielded to weariness. It cannot be expected to subside until the courts at least sketch out rough boundaries for the several economic areas to which the law is to apply. Yet persisting through the confusions are the two important facts ( $I$ ) that the basic intention of the law is clear enough and (2) that a large number of business men seem willing to give it some kind of practical effect. Facts such as these cannot but be influential. In this case they have probably resulted in a wide variety and degree of change in sales relationships involving discrimination.

The popular questions now beginning to rival those of legal interpretation are, "What is business actually doing?" and, "As a result of voluntary adjustments to date, what if any new pattern of price relationships is emerging?"

- A.B., I917, University of Pittsburgh; graduate study, 1921, Georgetown University. Economist, Dun \& Bradstreet, Inc. Formerly associated with National Recovery Administration as Executive Secretary, Advisory Council; Member, Policy Advisory Group, and Industrial Advisory Board; Chief, Domestic Commerce Division, United States Department of Commerce. Author of "Federal Trade Commission Decision in the Goodyear Case"; "Economic-Speculations on the Robinson-Patman Act"; "Evolution of Trade Practice Policy under NRA"; co-author of "Check-list of Possible Effects of the Robinson-Patman Act," and "Business Regulation by Judicial Decrec." Author of a number of brochures on forcign and domestic marketing problems, foreign affairs, and finance. 
The answers unfortunately cannot be much more assured than the opinions of the lawyers concerning what those answers wert intended to be. There is as yet no clear pattern. This fact in itself raises interesting questions. Why, nearly a year after its adoption, should so important an act not have produced responses sufficiently well-defined to permit a reasonably confident forecast of future trends? Does this tardiness argue that the principle of control over discrimination is in itself a well-intentioned error? Or that the amount of control needed is excessive? Or merely that the kind of control necessary to the purpose is such that it must mature slowly in the nature of things, and that impatience at this stage is thoughtless? Or that, irrespective of wisdom, the law was so vaguely drawn that confusion was its only sure consequence and will remain such as long as it stays on the books?

This article will not attempt to pass out tablets of stone on these issues, equivalent as they would be to a judgment on the whole experiment. It may supply evidentiary matter, however, by identifying some of the primary causes of delay, by recording some of the individual and group actions known to have been taken, and by pointing out circumstances that suggest the improbability at least of some of the extreme consequences sometimes depicted. One of the helps in understanding this legislation may be found in a study of why it doesn't jell more quickly.

Why is a comprehensive picture of business adjustments to the Robinson-Patman Act so slow in emerging?

\section{A. The Immensity of the American Market.}

A first, simple, and effective reason is that this is a big country. Our merchandising system is extremely elaborate, and the sheer assembly and verification of reports from all trade and industrial fronts woulld he a staggering task even if methodically planned. And within the writer's knowledge no such large scale enterprise has been attempted. Individual rumors and announcements are endless, but they are seldom checked as to accuracy or reduced to scale. They are valuable chiefly as food for thought.

This reference to the immensity of the American market is arithmetic only, and leaves to later consideration questions of complexity which play an even more important part.

\section{B. Legal Bewilderment.}

A more frequently recognized source of friction in the march of events is legal bewilderment. Perhaps it diffuses more than it retards. Even if everyone had set about remaking his policies on June 19, 1936, legal contrariety would have been sufficient to insure absence of pattern.

It would be futile to attempt a listing in this kind of treatise of the legal uncertainties involved. They have been pervasively, persuasively, deprecatingly and unremittingly aired during the past ten months. A few general observations suffice for the present purpose. 
This is the kind of law which to accomplish its aim, i.e., control of undue price discrimination, must control many of the steps by which sales are built up, such as advertising, brokerage, promotional aids, etc. Once committed to the enterprise, the lawmakers felt obliged at each step to reach out for the next, if they were not to be left in a state of animate suspension. Progressive embarrassment of this kind is by no means a novelty to the law, and does not prove that this law was all a mistake.

Basically the difficuity is in trying to fit a straight line purpose into the sworls of individual transactions. Even under the anti-trust laws there has been no simple test of legality. The courts examine each complaint in the light of the facts surrounding it, try to anticipate its consequences, and so determine the propriety of the accused practice. To the extent that Congress failed to make itself clear in this latest addition to the anti-trust laws (not to mention Section 3) presumably either the Act falls or has to be saved by judicial amendment. This means legislation by the tedious process of decree, and prolonged unsettlement for both lawyers and executives. Its clearest aspect is that when the lawyers and the courts get through with it, its spirit may, like that of the earlier anti-trust laws, be found to have taken on new and unexpected substance.

At any rate, business men realize that they can make two mistakes: the first in guessing what Congress intended; the second in guessing what the courts will do about what the courts guess were the Congressional intentions. Granting complete sincerity, they can do no more than look at the law's purpose, look at their private marketing tangles, address an inquiry to their conscience, and await correction. Exchange of views among themselves and in public discussion will flatten out personal variations to an extent that in the long run may be surprising, but the lines of uniformity are still too dim to be taken as the contours of a new system.

Another complication is that most sellers have probably not consulted lawyers at all, if for no other reason than expense. In this way they have avoided the divisions of the legal profession, but have probably invented more of their own. In the light of all the foregoing, and of certain technical considerations which will appear later, it seems likely that the one course on which many of the smaller sellers and buyers have unconsciously agreed is to do nothing. If this surmise is correct, it must have a place in the pattern of how business has so far adjusted itself to the Act.

It is at least evident that this law's vagueness has given an unusual amount of play to individualism in compliance. Uncertainty, conservatism, passion for reform, and trade strategy are four of the psychological horsemen riding the wide interpretive ranges of the Robinson-Patman Act. Small wonder that there is still no beaten path.

Mr. Patman, with his eyes fixed on the evils with which he is trying to deal, is not excessively concerned over legal technicalities. He brushes them aside by con- 
centrating his attention on purpose, and emerges with a simple analogy to the Golden Rule. This is interesting, but it raises a different set of problems.

The Golden Rule connotes morality and honor. Who could then object to its application to business? But unfortunately law and morality are not quite the same. Morality rests upon deeply inbedded but nevertheless abstract standards for human conduct, while law is both explicit and highly particularized. Its compulsions do not operate in the same way.

Morality is what it is because people feel in a certain way at a given period in a given environment. It belongs to the subtleties and imponderables of life rather than its codified whereas-es. It may be even more important but it has to be reduced to concrete enactment and precedents before people go to jail and pay fines for disregard of it.

This hesitation over an analogy is not an argument against the wisdom of attempting to curb excesses in price discrimination. It does seem to be a reason for confining argument to the more calculable domain of what the economic effects of this legislation will be.

\section{Complexity of Business Organization and Functions.}

An extremely important reason for the inability of business to make swift and uniform response to this law is found in its own diversification. The kind of variety referred to here is amassed by differing products, functions, trade and financial relationships, locations, and all the differences in competitive method that a few million human beings happen to think of. The forces of competition are eruptive and disorderly, and cast up strange shapes of merchandising just as volcanic action casts up strange geological formations. The collective effect on them of any one scheme of legal landscaping is hard to predict.

The probable need for greater care on the part of sellers in classifying their customers, is one illustration. In the field of wholesaling alone are full line and short line wholesalers, service wholesalers, cash and carry distributors, drop shippers, mutuals, chain stores, cooperatives, voluntary groups, desk jobbers, and many others. Most of these will fight for maximum recognition of their special services in terms of trade discounts irrespective of volume, and will resent any preference shown to the others. For administrative purposes these classes will have to be arbitrarily grouped and rated. The problem is not new but the consequences of error are now more serious. It is hardly likely that the Congress passed this law because it felt present habits of customer classification to be too careless, yet reform in this area could be one of its major effects. Such reform might be a little hard on some miscellaneous operators who have been getting on all of their business the best going discount for any service performed; and on those whose petty orders have been really a liability to their suppliers; and on still other members of the very class that Congress was trying to help. It is also hard on prophets. Improvements in classification might be entirely salutary from an economic standpoint, but they 
are of too slow growth to warrant a place for some time to come in any precise catalogue of "what is happening under this law"; even though some industries are already having special surveys made by independent agencies of their customers' methods of operation.

Part of the complexity arises from the fact that although business organization is mobile and business processes infinitely varied, the Act gives no clue as to where it expects necessary lines to be drawn. The conceptions we employ-wholesalers, jobbers, etc.; product groups; good, bad and intermediate credit risks; cost categories -are merely approximations for convenient reference. The graduations are usually continuous and most dividing lines arbitrary. "Likeness" between two products, one of the controlling concepts of the Robinson-Patman Act, begins with physical identity and ends with similar purpose. Where does the law cease to apply? Consider the peach and where it starts to differ with itself inside a can. Different size, different number of slices in the can, different amount of syrup, different flavor and quality? Or are all peaches just peaches? Or jumping to the opposite extreme, are all canned goods just canned goods, so that the canner must not discriminate between buyers of caviar and dog food? Of course not, but the majesty of the law may be ruffled occasionally before all such necessary lines are drawn.

The Act itself introduces a new variety of the degree problem, or rather intensifies an old, when it distinguishes between healthy and injurious competition. This involves both determination of the extent to which a particular discrimination contributed to injury and how much injury was done. Thus the product of an industry may be so unimportant to another product of which it eventually becomes a part, viz., buttons sold to clothing manufacturers, that the most erratic price policy could not be charged with causing injury to competition among the purchasers (although it is conceivable that a competing seller might have a case). But somewhere up the scale, presumably culminating in the piece goods themselves, the issue becomes acute.

Another brake on the evolution of this law, which in part stems from the intricacy of business organization, is the sheer inability of some sellers to extricate themselves from marketing jams into which they have been pushed by the pressure of circumstances over long years. Some- professional price-cutters, of the type irreverently referred to as "gyps," have by peculiarities of location, volume and method been able to jockey progressively lower discounts from their suppliers. These discounts have thrown the latters' price structures askew and become embarrassing both to them and to neighboring distributors. But no one dares to break loose from this kind of web unless competing sellers do likewise. The law merely adds to the discomfort of those entangled. Its threats, however dire, are still too potential to match the certainty of lost business and prestige in these sensitive spots. Barring a miracle of administrative speed, the only escape so far apparent would seem to be a conspiracy in restraint of trade to observe the Robinson-Patman Act, 
perhaps with the interesting result of the conspirators being jointly prosecuted for its violation. These marketing "hot spots" suggest anything but a limpidly serene process of adjustment, even though discrimination is open and severe.

It is evident that business is much more malleable in some areas and in respect to some practices than others, even under the pounding of a law. To the extent that such a law is drastic, its impress will be progressively uneven, and its early effects more apt to suggest a relief map of hard and soft spots in marketing topography than the operation of a national policy. These marketing, irregularities extend themselves into irregularities of time, insofar as rate and extent of adjustment are concerned.

Marketing seasons are also a factor. Industries with spring pricing can delay their decision longer than those from whom the law requires immediate decision. Lastly, the differing bargaining position of buyers and sellers in different trades results in dissimilar degrees and methods of compliance, avoidance and evasion which bear no relation to each other and therefore contribute to no pattern. On the contrary, some of them have run directly against the purpose of the Act, fitting into a pattern only as its reserve. Some of these will be considered in a later paragraph.

In short, as a result of the intricacies in business organization and functions the law seems certain to have different effects in an infinite variety of different situations. But there is also a subjective species of complexity to be dealt with, originating in the limitations of the human mind. Literal observance of this Act would require a body of technical knowledge which the average operator does not possess. This knowledge is of law, respecting new tests of legality for which for a long time there will be no familiar standards in commercial usage; and of economics, as in the necessity of determining when competition with another operator is being injured; and of costs.

From a practical standpoint the principal requirement of new knowledge is in the field of accounting. Cost determination, especially in distribution, has always been somewhat speculative and controversial, and perhaps the majority of systems in effect are primitive in comparison with the fine distinctions contemplated' by this law. During recent years costs have come in for an uncomfortable amount of emphasis from the average man's standpoint. During N.R.A. days "destructive price competition" was the current threat to civilization in many code sponsors' minds. It took many forms, and required scores of diverse controls, if the world were again to be made safe for business. These controls in turn required standards of measurement; and costs, perhaps the most dubious and doctrinal of all possible standards, were usually the final resort. Improvement in costing practice was not a primary aim, merely a means to an end. No more practical yardstick could be found. Now we have it again. No one will question the desirability of improving general understanding of costs, and in fact that may well be an excellent long term 
benefit from this Act. It is perhaps unfortunate however that for the immediate use of sellers trying to observe the law a less rubbery measure of right and wrong seems not to be available. Many unusual computations and allocations have to be made to check conformance with the law and some of them at least have to be matters of private opinion. It is apparent that for this reason alone the first year's adjustments must fall somewhat short of military precision.

These adjustments, once and however made, will be full of arbitrary stopping points and therefore of diversity. Quantity brackets cannot conceivably be cut so fine as to fit a gradual slope of savings. At the other extreme they can easily be made so wide as to offer no real choice to differently sized buyers, and to seriously penalize those lying just under a quantity line. Some industries may not be able to decrease costs at all with increasing demand, particularly when the cost of manufacturing is a substantial part of the sale price; whereas producers of specialties, proprietaries, etc., whose expense is principally in promotion, can accomplish real savings from quantity business.

The business complexity problem is heightened by the law's own pre-occupation with detail. It is a splicing rather than a coupling job, this joining of many legal strands with many operating details. It is intensive rather than defensive or pressure law of the type of earlier regulatory measures. Naturally the reaction of several million human beings to this kind of a change will be more confused and therefore slower to assume fixed form, even though some of the implications of the original anti-trust laws themselves are still in the world's list of unsolved problems.

The foregoing analysis perhaps does no more than affirm the generalities that a law must be appraised in terms not merely of its provisions but likewise of its setting; that there is necessarily a difference between law in books and law in action; and, possibly, that intimate control over complicated situations will tend to widen that familiar gap. There is no finality in such recognitions. The ends sought may be so important as to be worth the cost, and a good deal of legislative experimentation with details may be preferable to the simplicity of a more drastic attack. For instance, if the present flood of federal and state laws purporting to humanize narrow aspects of competition should fail of their purpose, the driving force in them might swing angrily on even more fundamental tenets of free competition. Government participation in management and limitations on size of business enterprise are at least within the post-depression war zone. As used here, the terms are merely abstractions, but in the peculiar temper of frustration it is only history that illconsidered blows can be struck. There may be reasons for trying to make this law work that are more important than irritation with its defects.

But despite confusions and alarms, protest and derision, things are happening under the new Act. The fact that they do not yet add up to a national pattern does not take away too much from their importance. A national pattern is not even essential to the Act's purposes. It was the highly publicized, extraordinary dis- 
criminations that aroused sufficient fear and anger to provoke this extraordinary legislation. Business generally is supposed to have disliked them, and to have been willing to see some kind of a halt called. It has even been suggested that if the law should lop off the excesses in price discriminations-and be indifferently applied elsewhere because of the congestion in government agencies and the inertia of business interests at the lower level-it might not correspond to ordinary conceptions of law but still be worth its keep. The threat of irresponsible triple damage suits mars this picture. But until interpretations appear this threat may remain merely potential.

\section{Suspected Happenings under the Robinson-PAtMan Act}

So far as is known, no formal inquiry has been made into the number and kind of policy adjustments initiated because of the Robinson-Patman Act that would cut across enough industries to be significant. No story of either slow or historic upheaval in the mass of business practices can therefore be recorded. Such impressions as have begun to take form have to rest on such evidence as can be drawn from trade periodicals, trade gossip, the talk of conventions, inquiries addressed to those who have made a special study of the law, and interchanges of views.among lawyers concerning the specific problems submitted to them. This kind of evidence yields a net sense of the trend of affairs rather than a laborious trade by trade build-up, and the product is correspondingly unstable.

Broad categories do have a tendency to take form in the observer's mind whether or not they would survive a methodical check. A division seems to appear for example between small sellers whose business is not of the kind likely to attract attention, and large sellers whose capacity to provoke resentment by their discriminations helped to bring about the Act. The first group must be dismissed rather briefly, There is reason to suspect that a good many small sellers listened gravely to expert analyses of the Act at their Convention and Rotary Club meetings, found it very interesting, agreed with the speaker that it either promised to restore honest competition or was a threat to free institutions, and hurried back to take care of the afternoon's mail. Where they happened to sell a substantial part of their output to large buyers, exceptions undoubtedly occurred. .And quite a few, to judge from trade comment, were sufficiently impressed to level off some of their more offensive concessions unless the business was too indispensable to them or buyers resisted too strongly. All of this to the extent that it was given to them to understand their rights and risks under the law.

It is with the actions of the larger sellers that most of the law's effects are principally concerned. Naturally more attention has been paid by this group to the warnings and advices with which the air has been filled since June Igth last. To hegin with they had lawyers. Beyond that, it seems likely that under the influence of Convention debate and more frequent personal contact fairly uniform attitudes on the more pressing issues tended to develop. Many of these men have made 
their guesses as to what the law means and tried to bring their more dangerous practices into line with its apparent requirements. With some of them this has probably been a matter of making minimum concessions, not exactly those that would bring them entirely within the law, but those that seemed capable of keeping the law from getting after them. As this distinction has been unclear legally, it was not regarded as fatal morally.

With a few of the largest consumer goods industries, however, particularly those enjoying strong leadership, study of the law has been intense, not only with a view to observance but likewise with the design of using its technical provisions to get better control of their marketing practices and loosen the grip of powerful buyers.

This of course is merely a summary of attitudes, the effect of which on prevailing selling practices and relationships throughout the country could still be diverse and lacking in pattern. It is at least speculatively interesting, however, to sift out of . these attitudes the particular subjects in which interest has run uniformly high. By tentatively giving this interest the standing of a clue to actions subsequently taken, we may venture on an appraisal of the Act's early effects in specific trade practice areas.

\section{Prices}

There seems to be little doubt that many concerns have made a real effort to simplify their price structures as a necessary first step to making them square with the law. This would necessarily involve a recasting of customer classes with some eliminations, and with a particularly hard and unfriendly look at existing quantity spreads. These are in themselves major economic considerations, however, and will be considered separately.

It is doubtful if any one can offer an opinion on whether the general price level has been raised or lowered because of this Act. Controversy has been particularly bitter on this subject, the opposing views being: (hostile to the Act) that prices would soar because the big buyer was deprived of the fruits of his efficiency, and (friendly to the Act) that what was involved here was the general balance of prices between buyers rather than total returns to the seller, and that the big buyer did not get his inside cut because of efficiency anyway. Propaganda has reached this commentator to both effects, allegedly supported by cases. It seems rather obvious that so many distinct and powerful forces have been acting on the price level during the past year that the effect of this single influence, if any, is incapable of isolation.

That the Act would give encouragement to one-price policies was forecast from the beginning. This is one of the easiest and surest ways of winning immunity from the law's penalties, or so it seemed to sellers predisposed to such a policy despite some small discord in the legal fraternity. Occasional instances come to light of manufacturers whose marketing strength has permitted them to put a one-price policy into effect and who have utilized the opportunity to do so. Others have approximated it more closely than in the past. No instances are known of whole 
industries moving on to such a plane, although where there has previously been strong trade sentiment in that direction it has certainly not been weakened by the new influence.

It has been frequently asserted since passage of the Act that open pricing, by individuals or by trades, would offer one of the surest defenses against trade suspicion and litigation, and that the many arguments already urged in support of such a policy would be effectively capped by this new incentive. Perhaps this would have happened if the legal status of open pricing systems had been clearer, and it may happen yet. The Sugar Institute decision, ${ }^{1}$ however, failed to leave a completely open door to the full-fledged open pricing system sought by most of those approving the principle, so that it is not likely that much growth in its use can so far be traced to the Robinson-Patman Act.

\section{Quantity Discounts}

There is some fairly definite evidence that extra wide quantity discount spreads have been narrowed since the passage of this Act and probably because of it. After all it was out of such discounts that much of the agitation for the Act had sprung, and it was to be expected that these extremes would be more sensitive to the law's glare and would shrink more quickly. This shrinkage has extended to previously liberal ways of computing quantity. In at least two prominent industries the percentage of manufacturers giving cumulative quantity discounts has been cut in half. Listing practices under which discounts were previously earned for aggregate quantities purchased by mass distributing units from an approved list, do not now carry their former authority. Many advices are being issued by legal and other competent authorities against granting quantity discounts on orders placed through central buying agencies. In each of these cases an insistent finger is pointed at actual cost of sale and delivery as the only acceptable test of an eligible discount.

One of the ironical by-products of this law passed for the uplift of small business has been that very small buyers have been occasionally checked off sellers' lists entirely or have been subjected to closer scrutiny than before with respect to whether or not their orders carried their weight. This kind of customer was endangered even before the Act by the rash of scientific cost allocation with which the distribution trades were successively breaking out. That these customers have found themselves cut off from sources of supply on a wide scale may be doubted for the reason that it is much easier to be careless than it is to be scientific, and in a pinch an order is always an order. Some of it has happened and if enforcement does bring about more exact accounting, the threat will become more acute.

\section{Accounting}

Improvement in accounting methods themselves is one of the most commonly expected by-products of the Act. That the subject has received more attention since the passage of the Act most accountants can testify. Unfortunately, however, there

\footnotetext{
${ }^{3}$ U. S. v. Sugar Institute, 297 U. S. 553 (1936).
} 
is no magic formula for distribution cost accounting; to a regrettable extent some of the key principles still belong to the field of theory; and many sellers have neither the equipment, staff or inclination to enter upon so difficult a task. These practical circumstances conspire in degree at least to temper the stimulus provided by the new law.

The principal reflection here, however, is that the amount of control over such matters necessary to carry out the literal intentions of the law, as defined in Congressional utterances, would be rather staggering. The stimulus may be overdone for best results. Distribution cost analysis by quantities, qualities, territories, customers and even special sales returns and profits from distinct promotional efforts would not be too much to supply the airtight protection against improper pricing for which the authors of these reports seemed to yearn. It goes without saying that no such degree of perfection will even be approximated, but there is nevertheless a great new stirring throughout business concerning methods of checking distribution costs.

\section{Terms of Sale}

This subject falls in the category of those about which great interest has been aroused by the Act without yielding any comprehensive evidence as to what has been done. A surprising number of inquiries to specialists on the law has been concerned with the problem whether or not dissimilar terms will be considered in violation of the Act. Forward datings and price anticipations made available to large buyers and not to small ones have caused uneasiness. What the law will finally say about this matter cannot be known, but it may be suspected from the interest shown that sellers are seeking justification for such differences in treatment before they extend it. The same reasoning applies to the charging of higher prices to poor, slow, or doubtful payers. The practice has been common and it had not occurred to most manufacturers to question its propriety. Its propriety is still not questioned but the law may not provide for such distinctions and it is probable that sellers here and there are being more careful.

One of the early drafts of the Act went out of its way to condemn unequal terms of sale, and even though the reference was finally deleted, its sponsors continued to insist that discriminatory pricing was not the way to take care of doubtful accounts. They argued that in the stead of this practice sellers could require cash or refuse to sell.

Surprising as it may seem, some manufacturers have actually discontinued cash discounts. This has been one of the preposterous-looking possibilities that a number of critics recognized during the first rush of argument. Obviously it could follow a hair-splitting construction of the Act. Not many really thought that it would happen on a large scale, nor do they yet. It is merely recorded here that the group that did take this action happened to be an important group, although so far its panic does not seem to have been contagious. Perhaps it was not panic, but an opportunity 
to eliminate this particular form of price concession that the group was powerful cnough to be able to exploit.

\section{Advertising Allowances}

Naturally enough, considering that real or alleged abuses in this field supplied a great deal of fuel for the anti-discrimination bonfire, results have bordered on the spectacular. In some industries such allowances were withdrawn completely and in others drastically curtailed. Latterly, there has been in evidence a creeping retura of them, sometimes in line with newly formulated principles and s metimes in the less scientific spirit of holding up a wet finger to the winds of enforcement.

Few words have vaulted into more sudden prominence than the words "proportionally equal." "Proportional to what?" is of course the core of the argument. The solution of making them proportionally equal to sales is attractive to the pure mathematician and repugnant to the seller with a prejudice in favor of his money's worth. Another of the straight mathematical solutions occasionally recommended is for the seller to assume a uniform percentage of all buyers' advertising expenditures. The more common drive however is toward a qualitative treatment of the word "proportionally," under which the seller would stipulate the services that he stood ready to buy, set up measurable specifications for them, and scale his allowances to those specifications. The legality of this solution must of course remain unsettled until the Commission and the courts pass upon it, for it reserves to the seller an amount of discretion that the law's draftsmen probably did not intend. There are very many variations of this scheme, but this seems to be its most popular form as developed to date.

There has been a good deal of talk of the practicability of separating advertising allowances completely from commodity sales and of contracting for them through third parties as in the case of other kinds of advertising. Some advertising agencies have made known their readiness to handle this kind of business but the extent to which contracts have actually been drawn is unknown.

The reaction of large buyers has of course been equally calculating and strategic. Some of them have kept up the pressure for allowances and are probably still getting them in one guise or another, presumably in such dress as to be legally plausible. There has undoubtedly been some private blacklisting of sellers who would not give desired concessions, and there has undoubtedly been an increased emphasis on some private brands to replace lines on which concessions were refused.

On the whole, it is probable that the scale on which advertising allowances were formally given has been reduced and that there has been greater insistence on actual performance of services for which payments are made. These are surface results. Beneath the surface, maneuvering for ultimate position is still going on. And it definitely cannot be said that a new equilibrium for advertising allowances is within near reach. 
The situation regarding demonstrators is less clear. A great many sellers, buyers and observers alike have shown a disbelief in the practicability of so dismembering demonstrators as to satisfy the letter of the law. They feel that the alternative of dividing these men's time into the rather minute fractions necessary to relate them to respective size of purchases would be unworkable from a management standpoint even if more humane. It will be noticed that quite a number of cases so far taken up by the Federal Trade Commission involve this issue.

\section{Brokerage}

Here is another of the issues arousing great bitterness in the past and which therefore has proved particularly sensitive to the new law. Brokers' organizations were among the law's most active sponsors and it is self-evident that they would be equally concerned over compliance. A survey conducted during the winter by the American Grocery Manufacturers Association indicated that the $20.6 \%$ of manufacturers paying brokerage direct before June Igth last had apparently dropped away to almost nothing, although the reduction in those making such payments to Voluntary Group Headquarters was only from $35.6 \%$ to $14.4 \%$.

This distinction points up one of the liveliest controversies that the law has yet spawned. There is still extant a respectable body of opinion that brokerage to co-operative headquarters remains legal. The argument runs that the members of such co-operatives retain their freedom of choice in buying and have to be genuinely sold by headquarters on particular brands, that such headquarters render assistance of unmistakable value to manufacturers through their merchandising aids, and that in their intermediate capacity they steady the course of trade and induce repeat business that without their efforts would go wandering over the supply field. Under the influence of this reasoning, rationalized to some extent of course because of the trade pressure accompanying it, many co-operatives are still continuing to demand and some sellers to give brokerage to the formers' central offices. That these robust convictions are not altogether untinged by doubt is suggested by such replies as the following one received in response to the Grocery Manufacturers' questionnaire"We are not accepting brokerage unless it comes through our national buying headquarters who have hired men to go to jail for us."

\section{Customer Classification}

It has been pointed out in an earlier paragraph that proper classification of customers might be usefully stimulated by this law. A letterhead on which some petty retailer has printed the words "Wholesaler" or "Jobber" is a familiar sight in many trades. Manufacturers have differed widely in the amount of care they have exercised over this important problem. Some have set up classes and have adhered closely to them, checking all suspicious claims. Others, either because orders were the first consideration or simply because of general looseness in the management, have taken business pretty much as they found it. Most students of marketing will agree that abuses in the field of customer classification are both common and diffcult to cure. From the sellers' standpoint they mean both lost income and irrita- 
tion in the trade. From the buyers' standpoint they mean a disorganized competitive situation at the next distributing level. Now, when a bona fide retailer, who lets the world know that he is that and nothing more, has to face the competition of another retailer receiving wholesale discounts, neither amity nor economics seem to be very well served. One of the dearest ambitions of many trades and industries during N.R.A. days was to clear up this "Classification Mess" as they regarded it. Their plans usually broke down, not on lack of sympathy in officialdom for efforts to thwart misrepresentation or ignorance, but on their insistence that rigid customer classes be made mandatory and not merely educational.

As soon as the beginnings of a trade practice policy emerged, N.R.A. was found unwilling to go so far, but the issue of more exact customer definitions has lingered on. Its sudden appearance here as a possible indirect requirement of the RobinsonPatman Act is interesting both in itself and as an unusually apt illustration of the extent to which close legal control over the details of a business can produce byproducts as well as primary crops. Some will be good and some bad, but which and how much of each is scarcely knowable in advance.

An attractive by-product of this particular by-product is promised, according to present indications, by the increased knowledge about customers that sellers will be forced to acquire. The point need not be labored as its implications are clear from the consideration of customer classes and trade discounts presented above. The interesting corollary however is that quite a number of manufacturers are now making special investi tions of their customers, or having them made for them, to find out whether they have been properly classified in the past. Their theory in doing this comes in three parts: (I) they will catch enough cases to more than pay for the cost of the examination in discounts saved, (2) at the same time they will be avoiding one of the perils of the Robinson-Patman Act, and (3) it's a good idea anyway.

\section{Protection by Certificate}

Many sellers and buyers are requiring assurances of each other that the transactions in which they mutually engaged do not trespass the law. Buyers have printed on their order blanks notations to the general effect that "it is understood the prices at which these goods are being sold do not contravene the Robinson-Pattman Act."

Some manufacturers, worried over their disorderly customer lists, have likewise stipulated on their invoices that "these prices are given on the condition that the goods in question are not directly resold at retail." Some sellers are requiring formal assurance from brokers that they are not representing buyers and that no part of the commission paid them will go to the other party to the transaction.

\section{Avoidance of the Law}

Mention of avoidance immediately brings the by-product aspect of law-making back to mind. It is one of the most important of all and one of the most uncertain in its ultimate consequences. 
Material for consideration under this heading is both rich and speculative, and a little too much so of both for condensed treatment. To give it a setting and for the sake at least of an interesting argument it might be said that the elementary purpose of the Robinson-Patman Act was to help independent wholesalers and retailers while the chances of lawful avoidance are slightly in favor of mass distributors. This tentative proposition is laid down on the assumption that the law can be avoided by such maneuvers as integration of manufacturing and distribution, the contracting by mass distribution for the entire output of small manufacturers, the further development of private brands, and the consolidation by mass distributors of their retail unit purchases where these have hitherto been too decentralized to claim economies permitted under the Act.

Extensive integration of manufacturing and distribution would obviously narrow the law's application, and to that extent deprive some types of retailers, wholesalers, and national brand manufacturers of its expected benefits. How much increase in this modern development we are going to see is still speculative. It deserves nevertheless to be recorded among the current effects of the Act that in attitude at least chain stores and mail order houses are giving an increased amount of attention to the possibilities. Unsubstantiated reports that they have here and there carried their interest to the point of actual new investment are not uncommon, and doubtless some of it has happened. Part of this new activity may be strategic only, for the purpose of preventing suppliers from at least leaning backward in their efforts to comply with the law. Some of it may be straight dollars and cents business calculation. A part of it is surely impulsive, bred by irritation with the law and an angry determination to be free of its restrictions. It does not follow that all of these new developments will be profitable or permanent. Both manufacturers and distributors have stubbed their toes in the past by walking too blithely into the other fellow's domain, and can easily do so again. This is theoretical and belongs to the future. The point of immediate interest is that the Robinson-Patman Act has supplied a fillip to such ambitions and that it shows signs of having some effect. Mr. Patman's own recognition of this danger is evidenced by his interest in an additional law to prevent manufacturers from selling at retail. Co-operatives and voluntary groups are feeling the same urge. As they are organized for the most part in the interest of their wholesale and retail members, it might be inferred that independents will thus be able to keep step with the mass distributors and nullify this particular advantage. The difficulty is that the co-operatives, with their less fully co-ordinated managements, will hardly be able to bind all of their units to these expensive ventures as freely as can the corporate institutions.

Possibly more dangerous to the intentions of the law and to independent retailers and wholesalers is the threat of full output contracting by mass distributors. Here again business is faced with the possible expansion, under a law to save small merchants, of large seale operaticns. This solution disposes of the worries of cost 
allocation, algebraic distribution of advertising allowances, and the other minutiae of justice with which the law concerns itself. There is but one buyer and one seller.

It might be argued that size is size and that if a chain or mail order house can swing so big a contract, so can the voluntary and co-operative. The flaw in this argument likewise lies in the poorer cohesion of the co-operative units. The members of the co-operative organization are still primarily individualists who have surrendered a certain measure of independence to the common good but will always retain enough of it, together with distinctive local needs, to make them shy of headlong commitments. Their mass distributing neighbors will, in the parlance of the day, not have any such problem of reserved powers, so that whatever their head offices say ought to be done for the system as a whole has a moderately better chance of being done.

Probably the most talked about new issue touching the effect of the Act on competition between mass distributors and independents is the extent to which it will give new life to private brands. These had experienced a considerable growth up to and during the depression. They are obviously of deep significance to the whole merchandising world. If the law "cracks down" too sharply on the price advantage which private label owners have been enjoying over national brands, additional incentive would be supplied to such owners to turn to exclusive sources for their supplies where no problem of discrimination could enter. $\dot{A}$ second and even more important result might occur in the mass distributing outlets themselves. Heretofore advertising allowances have operated as a check on private brands to the extent that they supplemented profit margins resulting from the quantity purchases of national brands. If these are now heavily curtailed it is not unreasonable to expect that intensified point-of-sale pressure will be thrown by these distributors behind their own labels. Some chain stores have already made clear their ability and readiness to meet the new challenge by such a shift of emphasis. It does not follow that the choice will be a completely free one. National advertisers know how to fight for their markets, and whatever funds are released by the curtailment of advertising allowances can be thrown into either enlarged advertising appeals to consumers or into lower prices. Instances of such reprisals are already known. In fine, the whole broad expanse of this traditional struggle has been newly agitated by the Robinson-Patman Act, and the outcome may be at once one of the most important effects of the new legislation and one least foreseen by its enactors.

One of the most interesting but more speculative consequences of the law may be the development of conversion contracts. Under this form of contract the buyer makes his own purchases of raw materials and turns them over to the manufacturers for processing. Title does not pass and presumably there is no sale of commodities to which to apply the law. In another sense a manufacturer merely rents out his processing facilities to the mass distributor. This procedure involves technical diffculties that somewhat belie its apparent simplicity and may not completely escape 
the reach of the law. Much depends upon the amount of respect shown by the courts to Congress's intention to outlaw "indirect" discriminations as well and to make the word "indirect" means a good deal. Resort to this device by one or two large companies has been reported to the writer, and that there is a good deal of interest in the possibility is attested by the number of inquiries being made in various quarters concerning it. However, it is doubtful if many contracts have been actually written.

It is quite clear from the above discussion that reactions to the Robinson-Patman Act are as wide and diversified as business itself, and that furthermore many of the adjustments now being made are tentative and experimental. Sellers must make their guesses as to the meaning of the law's specific restrictions, and will ultimately consult their own interests and prejudices. in choosing from among the various interpretations offered. These judgments will be further conditioned by buyers' pressure. Still further, when sellers act buyers will react, so that there will inevitably be give and take within and at least slightly over the boundaries of the law before any new set of usages takes hold.

\section{The Conservative Outhook}

A great deal of attention has been paid in this article and generally to the unusual number of "degree" problems with which this law abounds." The theory of most of the law's tests, as has been seen, is that there are invisible points beyond which normally healthy practices become harmful. Irritating though these problems are, it is the feeling of many observers that they are not necessarily fatal. Arbitrary distinctions between "degrees" are not at all novel to the law. The history of the Anti-Trust Laws is replete with them and the writing of meanings into and out of statutes and constitutions for better or worse is now standard jurisprudence. Perhaps never has the exercise of this judicial privilege been more heavily dramatized than in the recent Washington Minimum Wage Law and Wagner Labor Relations Act decisions.

The degree argument in the case of the Robinson-Patman Act can therefore be overdone. One of the risks in analyzing a regulatory law, however impartially, is that in admitting the administrative and interpretive problems of bracketing degrees of difference where no natural dividing lines exist, too much blame is laid on that particular law. Much of the difficulty lies in the nature of law itself, as a social and not always flexible instrument designed to keep surging human affairs in less disorder than they would otherwise be.

When Congress gets in one of its impulsive moods with reference to a semiscientific subject such as distribution, generalities can conceivably be less dangerous than too much precision. In such situations, for it to express all of its passing emotions in finite rules might be rigidifying beyond all tolerance and safety. Also; out of a welter of things to stipulate, it would be easy to the point of likelihood for it to pick on the wrong ones. For instance, it might have insisted in so many words that advertising allowances should be sprayed over the market in exact proportion 
to money sales, unaware or unmindful of the major injustices that would have to be suffered by commerce to produce the minor justice. Or that loss of three accounts by one seller to another should be proof of injury to competition. Most legislative proposals have at least a modicum of plausibility in them. It is only human nature to think of an entire situation in terms of the aspect that one is sympathetically viewing at the minute, and legislators are no exception. The result, of course, in the improbable event of complete lack of restraint, could be perfection by inches and distortion by the yard, after the fashion of the tailor who makes the suit look fine in front by gathering in the back.

At any rate the courts probably have the power to whittle down this particular law to dimensions and areas of application that most men will consider reasonable. They may choose to ignore minor infractions through a strict interpretation of what constitutes "injury." It is conceivable for example that disparities in credit terms will be disregarded unless there is unmistakable evidence of their consistent and deliberate use to bestow advantages on certain customers; that functional discounts will escape challenge unless out of all reason; that there will be no insistence on fine spun diffusion of advertising allowances; that the occasional and incidental violation will be regarded as without meaning or economic effect.

Legislation by judicial distinction between degrees therefore has something to be said for it, particularly in restless times. Congress filled this law with vague terms, which bewildered everyone but at the same time saved them from some myopic particulars that could have been even more embarrassing. As matters now stand, it is left to the more deliberate judgment of the courts to write equity into the new standards. Such a complete division of labor in law making may not have been exactly what the Fathers had in mind, but this time Congress invited it.

And this time the power to resolve uncertainties may turn out to be the power to save the good in the Act, as has happened more than once. A few conservative decisions could divert business men's attention from the welter of detail that now torments them and bring it back to respectful and sympathetic regard for the law's understandable purpose. Even in this fuzzy period between the passage of a startling law and its clarification critics recognize that there is quite a difference between fulfillment of that purpose and a hypercritical application to every possible situation. The second may come in time but the first does not have to wait on it. In spite of all the posing of ridiculous and possible problems with which the law's literature to date has been so rich, one can go further and say that not even yet have all possible causes of action been thought of. Nor will this process of individual experience and challenge run its course until long after business has selected for itself a set of practical assumptions, based on early court decisions and its own idea of the kind of justice that the law intends, and in the main settled down.

What the processes of democratic law making can do to a principle is always fascinating but those so inclined are still justified in keeping their attention fixed on the main idea. 